\title{
Control of Unit Power Factor PWM Rectifier*
}

\author{
Meifang Xue, Mingzhi He \\ School of Electrical Engineering, Beijing Jiaotong University, Beijing, China \\ Email: xuemeifang12@gmail.com
}

Received March, 2013

\begin{abstract}
To solve the problem of harmonic pollution to the power grid that caused by traditional diode rectifier and phase controlled rectifier, the unit power factor PWM rectifier is designed. The topology structure of the rectifier circuit is introduced and the double closed-loop control strategy in three-phase stationary coordinate system is analyzed. For the deficiency of control strategy, the control strategy in two-phase synchronous rotating coordinate system is proposed. This makes the independent control of active current and reactive current to be realized. The simulation model of the PWM rectifier is built and the effectiveness of the control method proposed in this paper is verified by simulation.
\end{abstract}

Keywords: Control; PWM Rectifier; Unit Power Factor; d, q Coordinates

\section{Introduction}

Unity power factor PWM rectifier has the advantages of high power factor, low harmonic content of grid side current, energy bidirectional transmission etc, is widely used in AC drive, reactive power compensation, active power filter, unified power flow control, as well as uninterruptible power supply, etc[1]. This paper introduces the topology of three-phase PWM rectifier, and describes the control method of the rectifier in three-phase static coordinate system. On the basis of the analysis of the advantages and disadvantages of this control method, the control method in two-phase synchronous rotating coordinate system is put forward. Then the mathematical model of three-phase PWM rectifier in d, q coordinates is established and the single control of active current and relative current is realized.

\section{The Control Method of Three-phase Voltage Source PWM Rectifier in Three-phase Static Coordinate System}

Figure 1 shows the topology of three-phase voltage source PWM rectifier, $e_{a} e_{b} e_{c}$ is three-phase voltage source, $\mathrm{C}$ is the dc side filtering capacity and $R_{L}$ is the load.

In order to realize the control of input current and output voltage, the traditional method is controlling the three-phase input current directly. The control of the input current is also the control of the flow of energy, thus the control of the output voltage can be realized. The control method of PWM rectifier in the three-phase sta-

*Project Supported by National Natural Science Foundation of China (51207008) tionary coordinate system is shown in Figure 2.

In this control method, the outer loop controls the DC voltage. The difference value of the command signal and actual signal of DC side voltage is imported to PI regulator. The output value of PI regulator is DC current signal $I_{m}, I_{m}$ is proportional to the amplitude of AC input current. So the command signal of three-phase AC current $I_{a} *, I_{b} *, I_{c} *$ can be obtained by separately multiplying $I_{m}$ by sinusoidal signal whose phase is the same as three-phase voltage. The difference value of command current and actual current is imported to PI regulator, and the sinusoidal modulation wave can be deserved. By comparing the sinusoidal modulation wave with carrier wave, the PWM wave which can control the switch can be deserved.

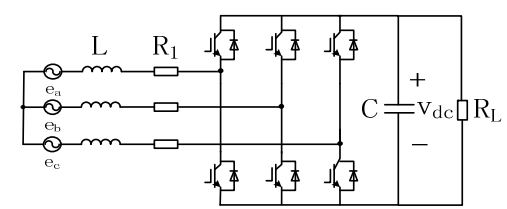

Figure 1. The topology of three-phase voltage source PWM rectifier.

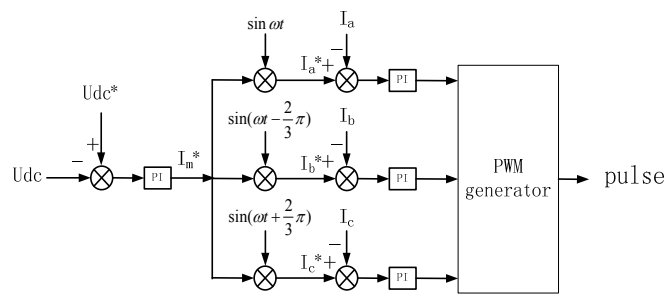

Figure 2. The control method of PWM rectifier in threephase stationary coordinate system. 
This control method is simple, but the command current in control system is a varying sine time-varying signal which has a certain frequency, amplitude and phase angle. The effect of steady-state performance is not desirable, and the independent control of the active current and the reactive current can't be achieved[3].

\section{The Control Method of Three-phase Voltage Source PWM Rectifier in Two-phase Synchronous Rotating Coordinate System}

In order to realize the non-static error control of threephase current and independent control of active current and reactive current, the control method of unit power factor PWM Rectifier in two-phase synchronous rotating coordinate system will be introduced.

Figure 3 shows the control method of unity power factor PWM rectifier in dq rotating coordinate system. Through coordinate transformation, three-phase stationary coordinate system $(a, b, c)$, can be converted to synchronous rotating $(\mathrm{d}, \mathrm{q})$ coordinate system that synchronous rotate with the grid fundamental wave[2]. The transformation matrix is:

$$
C_{3 s 2 r}=\sqrt{2 / 3}\left[\begin{array}{ccc}
\sin \theta & \sin \left(\theta-120^{\circ}\right) & \sin \left(\theta+120^{\circ}\right) \\
\cos \theta & \cos \left(\theta-120^{\circ}\right) & \cos \left(\theta+120^{\circ}\right)
\end{array}\right]
$$

The inverse transformation matrix is:

$$
C_{2 r 3 s}=\sqrt{2 / 3}\left[\begin{array}{cc}
\sin \theta & \cos \theta \\
\sin \left(\theta-120^{\circ}\right) & \cos \left(\theta-120^{\circ}\right) \\
\sin \left(\theta+120^{\circ}\right) & \cos \left(\theta+120^{\circ}\right)
\end{array}\right]
$$

The most prominent advantage of this transformation is the fundamental sinusoidal quantitative in $(\mathrm{a}, \mathrm{b}, \mathrm{c})$ coordinate system can be converted into a DC variable in $(d$,

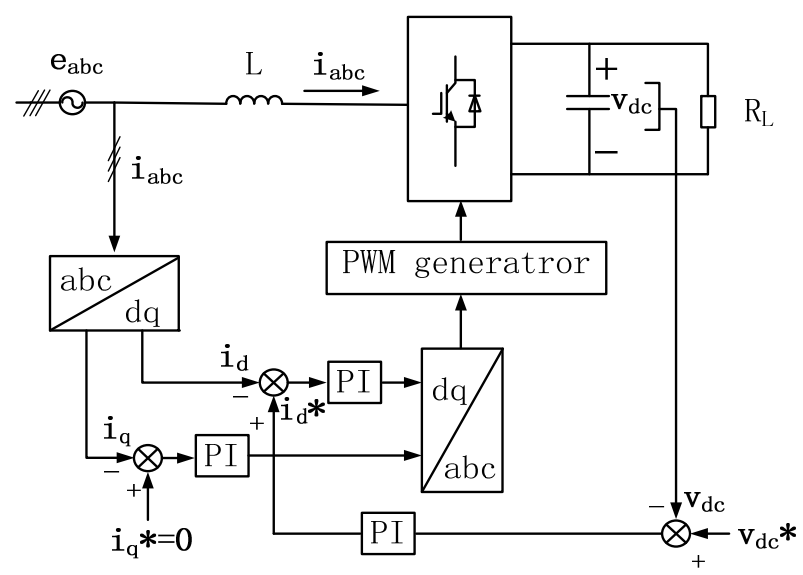

Figure 3. The control method of PWM rectifier in dq rotating coordinate system. q) Coordinate system. In this transformation, the d-axis in two-phase synchronous rotating coordinate system represents the active component, and the q-axis represents the reactive component. If we take the position of input voltage vector as the positive direction of d-axis, and the three-phase input voltage can be written as:

$$
\left\{\begin{array}{l}
e_{a}=U_{m} \cos w t \\
e_{b}=U_{m}\left(\cos w t-120^{\circ}\right) \\
e_{b}=U_{m}\left(\cos w t+120^{\circ}\right)
\end{array}\right.
$$

Through coordinate transformation the power supply voltage in dq coordinate system can be written as:

$$
\left\{\begin{array}{l}
e_{d}=U_{m} \\
e_{q}=0
\end{array}\right.
$$

According to the instantaneous power theory, the instantaneous active power $\mathrm{p}$ and reactive power $\mathrm{q}$ of the system is:

$$
\left\{\begin{array}{l}
p=\frac{3}{2}\left(e_{d} i_{d}+e_{q} i_{q}\right) \\
q=\frac{3}{2}\left(e_{d} i_{q}-e_{q} i_{d}\right)
\end{array}\right.
$$

Because $e_{q}=0$, the equation (5) can be simplified as

$$
\left\{\begin{array}{l}
p=\frac{3}{2} e_{d} i_{d} \\
q=\frac{3}{2} e_{d} i_{q}
\end{array}\right.
$$

If we don't consider the fluctuations in grid voltage, $e_{d}$ is a fixed value. So the instantaneous active power $\mathrm{p}$ and instantaneous reactive power q of PWM rectifier is proportional to $i_{d}$ and $i_{q}$. So that by controlling $i_{d}$ and $i_{q}$, the active and reactive power of PWM rectifier can be controlled[4].

In three-phase PWM rectifier, the input instantaneous value of active power in the DC side is $p=u_{d c} i_{d c}$, if the loss of PWM rectifier is not considered, from equation (6), we can know that $u_{d c} i_{d c}=p=\frac{3 e_{d} i_{d}}{2}$. When the grid voltage is a fixed value and the loss of rectifier is ignored, the DC side voltage $u_{d c}$ is proportional to $i_{d}$, so that DC side voltage of PWM rectifier can be controlled by the control of $i_{d}$.

The control method shown in Figure 3 also consists of voltage outer loop and current inner loop. Introducing DC feedback and the non-static error control of DC voltage can be realized. Due to the DC voltage can be controlled by the control of $i_{d}$, the output value of voltage outer loop of PI regulator is the reference value of current inner loop, so that the active power of PWM rectifier can be adjusted. The reference value of reactive 
current is based on the reference value of reactive power, so when $i_{q}{ }^{*}=0$, PWM rectifier operates on unit power factor state.

In this control method, the PI regulator can realize nonstatic error control. Compared with the control method in three-phase static coordinate system, the steady state performance is better. At the same time, the independent control of active current and reactive current can be realized[5].

\section{The Simulink Results}

MATLAB/SIMULINK is used to establish the simulation model of PWM rectifier. Simulation parameters are as follows: the voltage of power grid is $380 \mathrm{~V} / 50 \mathrm{~Hz}$. the inductance in $\mathrm{AC}$ side is $0.8 \mathrm{mH}$. The given value of DC side capacitor voltage is $700 \mathrm{~V}$. The resistance load is $3.72 \Omega$. Figure 4 shows the three-phase input current wave and its FFT analysis of unit power factor PWM rectifier under the control of three-phase static coordinate system. Figure 5 shows the three-phase input current

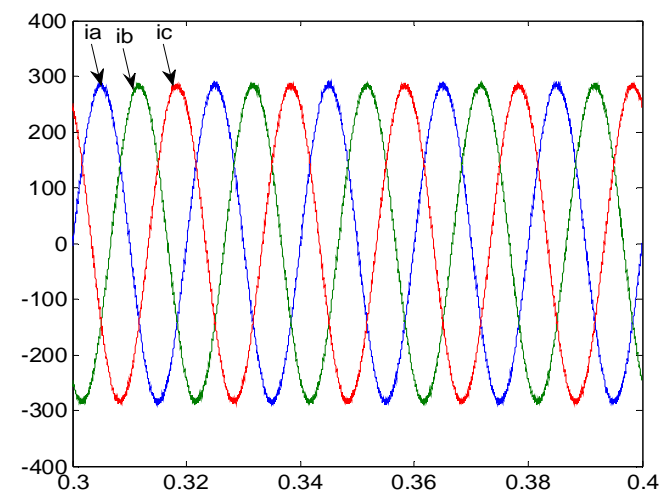

(a) Three-phase input current wave under the control of three-phase static coordinate system

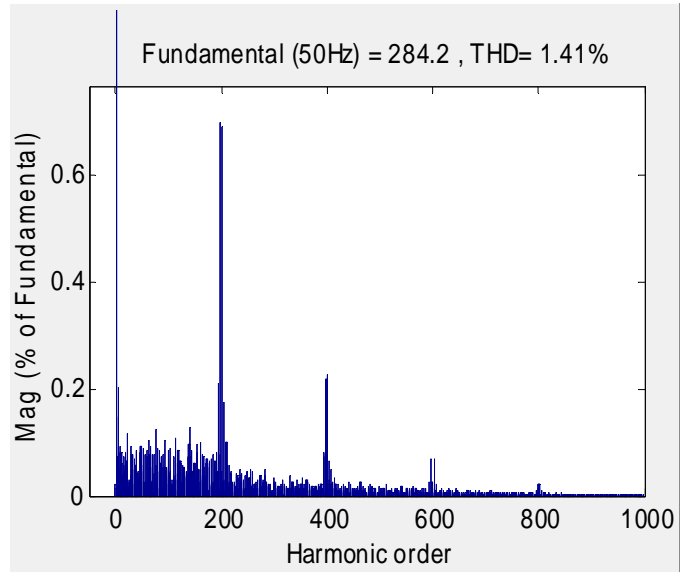

(b) FFT analysis of input current under the control of three-phase static coordinate system

Figure 4. Three-phase input current wave and its FFT analysis of unit power factor PWM rectifier under the control of three-phase static coordinate system.

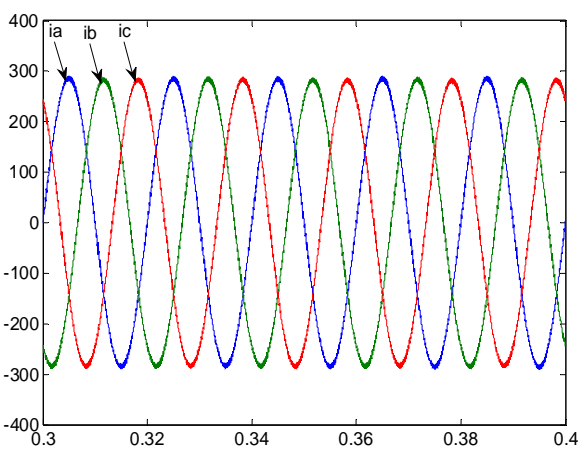

(a) Three-phase input current wave under the control of two-phase synchronous rotating coordinate system

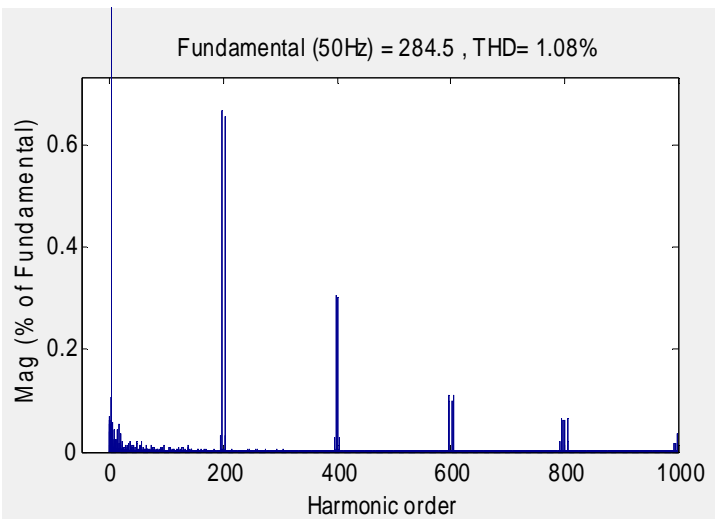

(b) FFT analysis of input current under the control of two-phase synchronous rotating coordinate system

Figure 5. Three-phase input current wave and its FFT analysis of unit power factor PWM rectifier under the control of two-phase synchronous rotating coordinate system.

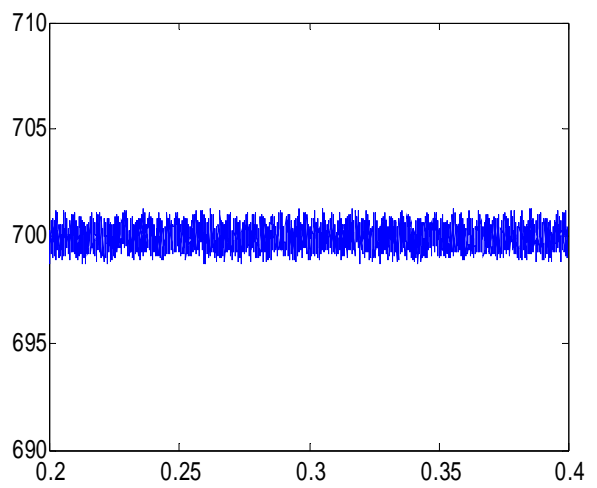

Figure 6. DC side capacitor voltage in two-phase synchronous rotating coordinate system.

wave and its FFT analysis of unit power factor PWM rectifier under the control of two-phase synchronous rotating coordinate system. Figure 6 shows the control effect of DC side capacitor voltage in two-phase synchronous rotating coordinate system. It can be seen from the FFT analysis of current waveform that control in twophase synchronous rotating coordinate system has a better steady state response than control in three-phase static 
coordinate system.

\section{Conclusions}

This paper respectively introduced the control strategy of unit power factor PWM rectifier in three-phase static coordinate system and two-phase rotating coordinate system, and the two control method are compared. Theoretical analysis and simulation results show that the control in synchronous rotating coordinate system has better steady state performance.

\section{REFERENCES}

[1] K.-N. Areerak, S. V. Bozhko, G. M. Asher and D. W. P. Thomas, "DQ-Transformation Approach for Modelling and Stability Analysis of AC-DC Power System with Controlled PWM Rectifier and Constant Power Loads," International Power Electronics and Motion Control Conference, 2008, pp. 2049-2054.
[2] Z. Zheng, C. Wang and X. P. Jing, "Comparison of Two Control Strategy for Three-Phase Voltage Source PWM Rectifier," International Conference on Computer and Communication Technologies in Agriculture Engineering, 2010, pp. 101-104. doi:10.1109/CCTAE.2010.5544851

[3] K. Wei and F. Xiao, "The Improvement of Current Feed-forward Control Strategy on Voltage Source PWM Rectifier," International Symposium on Computational Intelligence and Design, 2010, pp. 107-109.

[4] S. R. Naidu, D. A. Fernandes and K. P. Medeiros, "Simplified Control of a Three-phase PWM Rectifier," Proceedings of the 2011 International Conference on Power Engineering, Energy and Electrical Drives, Torremolinos (Málaga), Spain, May 2011, pp. 2758-2761.

[5] J. G. Zhang, B. Yang, G. Zeng and Y. Y. Tian, "A Unity Power Factor Control Method of PWM Rectifier," Power and Energy Engineering Conference (APPEEC), Asia-Pacific, 2012, pp. 1-4. 